\title{
ASO Visual Abstract: Impact of Tumor-Derived DNA Testing in Peritoneal Lavage of Pancreatic Cancer Patients with and Without Occult Intra-abdominal Metastases
}

\author{
Kazuharu Chiba, MD, PhD ${ }^{1}$, Tatsuo Hata, MD, PhD $^{1}{ }^{1}$, Masamichi Mizuma, MD, PhD $^{1}$, \\ Kunihiro Masuda, MD, PhD $^{1}$, Shuichi Aoki, $\mathrm{MD}, \mathrm{PhD}^{1}$, Tatsuyuki Takadate, $\mathrm{MD}, \mathrm{PhD}^{1}$, \\ Kei Kawaguchi, MD, PhD ${ }^{1}$, Kei Nakagawa, MD, $\mathbf{P h D}^{1}$, Takanori Morikawa, MD, $\mathbf{P h D}^{1}$, \\ Fuyuhiko Motoi, $\mathrm{MD}, \mathrm{PhD}^{2}$, Toru Furukawa, $\mathrm{MD}, \mathbf{P h D}^{3}$, and Michiaki Unno, $\mathrm{MD}, \mathrm{PhD}^{1}$ \\ ${ }^{1}$ Department of Surgery, Tohoku University Graduate School of Medicine, Sendai, Japan; ${ }^{2}$ Department of Surgery I, \\ Yamagata University Graduate School of Medical Science, Yamagata, Japan; ${ }^{3}$ Department of Investigative Pathology, \\ Tohoku University Graduate School of Medicine, Sendai, Japan
}

Tumor-derived DNA was detectable in peritoneal lavage, even in patients with pancreatic cancer without occult metastases. The presence of tumor-derived DNA as a molecular residual disease marker could help to predict the presence of subclinical micrometastases and estimate the risk of recurrence and worse survival (https://doi.org/ 10.1245/s10434-021-10997-w).

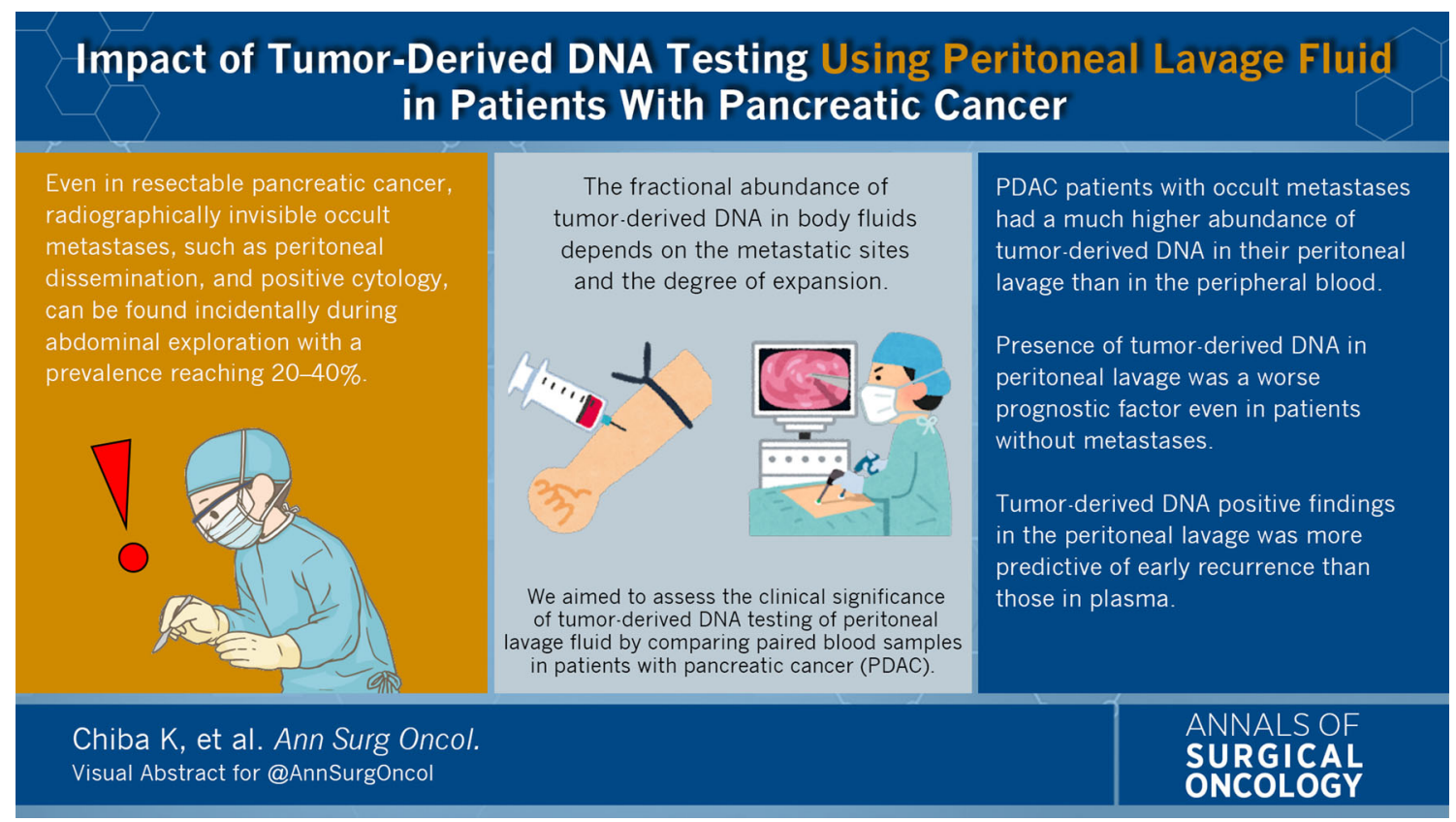

(C) Society of Surgical Oncology 2021

T. Hata, MD, $\mathrm{PhD}$

e-mail: hatata@surg.med.tohoku.ac.jp
DISCLOSURE Michiaki Unno, Takeda Pharm, Taiho Pharm, authors declare that they have competing interests

Publisher's Note Springer Nature remains neutral with regard to jurisdictional claims in published maps and institutional affiliations. 